\title{
'EVERYBODY IS AVAILABLE TO THEM': SUPPORT MEASURES FOR MIGRANT STUDENTS IN IRISH SECONDARY SCHOOLS
}

\begin{abstract}
Migration to Ireland is continuing, albeit at a much slower pace, and migrant children continue to have a strong presence in Irish schools. How well these students integrate into the Irish education system depends, at least partially, on the support measures the schools have put in place for them. This article draws on the results of a large-scale empirical study on academic and social support measures available in Irish secondary schools, and contributes to the debate on challenges, in terms of inclusivity, posed by immigration into Ireland. The paper discusses approaches taken at government and school level in addressing the needs of new arrivals, offering a comparative perspective of various support models in the EU. While there is a growing body of research on the experiences of migrant children and young people in schools, few previous studies have drawn on a nationally representative dataset and focussed specifically on the support measures migrant students can have access to.
\end{abstract}

Keywords: migrant students, secondary schools, Ireland, support 


\section{INTRODUCTION}

Schools have an important role to play in integrating migrant students (European Commission, 2008). Existing studies have shown that migrants are disadvantaged across a number of areas. These include access to certain types of schools, pathways available within the education system, drop-out rates and other educational outcomes (Author 3 et al., 2012; Heckmann, 2008). Policies and practical measures undertaken to address these issues tend to vary across Europe, depending on the migration history of these countries.

There is now an extensive literature on inclusive education, and on the impact of school effectiveness, school improvement and the ethos of the school on student social and academic outcomes. While some scholars tend to focus on the effectiveness of school-level factors on academic performance, others perceive supportive and caring schooling environments as a set of complex arrangements that assist learners in their academic and socio-cultural development (Lizzio et al., 2002). However, there seems to be a consensus among authors that effective schools tend to create a safe and supportive environment, the main components of which include: academic, social and linguistic support for students; student-centred learning practices; effective shared leadership; supportive staff; positive social interactions between teachers and students; and parental involvement (Bradshaw et al., 2012; Gorard, 2013; Kitching, 2012). Such environments are likely to help to improve student outcomes, particularly in the case of newly-arrived migrant students and their parents, who need assistance in adapting to the new environment, culture, and academic practices.

Exploring academic and social support measures in the Irish context is important for a number of reasons. Firstly, increased ethnic, linguistic, and religious diversity in Irish schools due to relatively recent large-scale immigration makes Ireland an interesting case study. Similar to other new migration destinations such as Italy and Spain, Ireland has seen a threefold increase in the number of migrant students since 2000. At the same time, the majority of state-funded primary schools and a significant proportion of secondary schools are denominational, primarily Catholic, indicating continued influence of the Church on educational matters such as school enrolment policies, hiring teachers and the provision of religious education. Secondly, social transformations in Ireland coincided with the economic downturn; this impacted on public spending, diminishing resources for education and migrant integration. In order to ensure that migrant children have the same life chances as native Irish children, the availability of targeted support measures at State and school level is essential. Furthermore, in the Irish case, the category 'migrant student' is far from homogenous. The 
vast majority of the migrant population comprises nationals from EU countries, followed by nationals from non-EU countries, unaccompanied minors, children who were granted refugee status, and asylum seekers. Pupils in Irish schools come from over 160 countries and for over 70 per cent, English is not their first language (Department of Education and Skills, 2011).

This article builds on existing literature on the education of migrant children by discussing the provision of such support measures in Ireland. In order to contextualise the Irish findings, it provides an overview of educational support available to newly-arrived migrant students in other countries in Europe in the context of inclusive education. The article focuses on secondary schools, because a large proportion of newly-arrived migrants in this sector have been found to have very low English proficiency (Smyth et al., 2009), and insufficient subject-specific vocabulary is likely to make preparation for the two State exams particularly challenging. ${ }^{1}$ Difficulties can also arise in the social sphere, as the new arrivals need to negotiate already established peer groups.

This article addresses the following questions: What educational support is available to all students in Irish secondary schools? What measures are specifically targeted at migrant students? How satisfied are school principals and teachers with the academic and social support initiatives their schools are able to provide? These questions constitute part of ongoing debates in Ireland. While the paper is set in an Irish context, the findings are likely to be of interest to other countries with a large proportion of newly-arrived migrants. It is structured into five sections: the first provides an overview of existing research on inclusivity. The second section offers a comparative perspective on support measures in selected European countries. The third section discusses migration trends in Ireland as well as the structure of the Irish secondary educational system, including targeted support available for students. This is followed by an outline of the methodology underpinning this article. The fourth section discusses our research findings, and the final section assesses our research results and points toward implications arising from this study.

\section{THEORETICAL UNDERPINNINGS}

The influx of migrant children has led to targeted support measures in various European countries. Of particular note is that supportive schools are often synonymised with inclusive schools. In practice, more supportive schools would mean more inclusive schools. Thus, a 
shared understanding of the concepts of inclusion and integration is an important starting point for our debate on school supportiveness.

Notions of inclusion and integration are recurring themes in the political, educational and social landscape. The concept of inclusion replaced the term 'integration', which had historically been used with regard to the placement of children with special educational needs in mainstream schools (Armstrong, 2009). While the integration model was largely based on providing support for individual learners to enable them to 'fit in', the inclusive education movement is based on equal rights to recognition and respect regardless of difference.

The review of the theoretical discourses on integration and inclusion warrants a number of observations. Firstly, while the principles of an inclusive education are based on tolerance, diversity and equity with an emphasis on maximising participation, it is very difficult to come up with one single, universally applicable definition that would reflect the complex nature of inclusive education (Ainscow, 1999; Booth et al., 2000; Winter and O'Raw, 2010). Secondly, regardless of different discourses concerning an inclusive approach (see Winter and O'Raw, 2010), inclusive education consists of providing resources to support learning and participation for curricular and extra-curricular activities (Booth et al., 2002; Ainscow et al., 2006), with teachers playing a central role in promoting inclusive education. More importantly, the evidence of successful inclusion should always be reviewed from a rights and not an efficacy perspective (see Booth, 1996). Finally, all these concepts touch on issues of capacity in each school to celebrate difference and to support the needs of each individual student. Inclusivity is, however, closely linked with the school culture and a supportive school environment (see Corbett, 1999).

The importance of the school environment and support structure for all children

Caring and supportive schools are settings designed to provide academic and pedagogical support to students (Hersi, 2011). Practically, in line with inclusive education, it also means using diverse strategies and working at many different levels on whole-class tasks, often without adequate resourcing and sharing specialist skills (Corbett, 2001). The provision of formal (e.g. learning support) and informal (e.g. extra-curricular) support tends to have a positive impact on students' academic and social development (Fertig, 2012). Previous studies suggest that efforts by school staff to create a supportive climate are likely to encourage student engagement, and prevent bullying (Eliot et al., 2010). In addition, supportive schools contribute significantly to the health and well-being of children through 
empowerment and participation (Konu and Rimpela, 2002; Osterman, 2000). A number of studies have shown that successful participation in school life is associated with school composition, and that, in addition to peer group dynamics, the socio-cultural context of the school matters (Author 2, 2010). Where the proportion of students from lower socioeconomic backgrounds is high, migrant students are found to have fewer targeted supports available to them (Cebolla-Boado, 2007; Rangvid, 2007). Following the growing recognition of the importance of parental engagement and home-school partnerships in creating supportive schooling environments, schools in European countries have increasingly focused on outreach to migrant parents by providing language support, and encouraging migrant involvement in parent-teacher associations (see Barg, 2013).

\section{The relevance of State policy and targeted support measures}

Existing research shows that schools differ in how they adhere to the needs of the newlyarrived migrant pupils, in the sense of general supportiveness and in catering for emotional and spiritual needs of the student body (see Bragg and Manchester, 2011; Devine et al., 2013; Kitching, 2012). It could be argued, however, that schools in their attempt to cater for newlyarrived migrant pupils of different backgrounds, faith and language competence, are facing a number of challenges in terms of inclusivity.

Over the decades, the migrant receiving countries have introduced and implemented various national support measures that target migrant students. As shown in a recent largescale comparative study, Educational Support for Newly Arrived Migrant Children (NAMS), there are a number of different approaches adopted across Europe with regard to educational and social support for newly-arrived migrant children (European Commission, 2013). The study compared the educational support models of fifteen European countries (Austria, Belgium, Czech Republic, Cyprus, Denmark, France, Germany, Greece, Ireland, Italy, Luxembourg, Norway, the Netherlands, Sweden, and the United Kingdom) based on both targeted and non-targeted support measures comprising linguistic support, academic support, outreach and cooperation, and intercultural education (see Figure 1). The figure shows the dispersion of countries across the four support measures, differentiating country clusters with similar characteristics for educational support.

$$
\text { [--- Figure } 1 \text { about here ---] }
$$


One might expect that a longer history of dealing with migration would have resulted in more dynamic systems being put in place at a national level for supporting migrant children. However, that is not necessarily the case. For example, Denmark and Sweden became popular new migratory destinations following the EU enlargement, subsequently providing quite comprehensive linguistic support for migrants. In contrast, France and Luxembourg countries with a longer history of immigration - are driven by an integrationist approach. For example, religion is integrated into subjects such as history and philosophy; it is presented as a 'contribution to human civilization' (Mannitz, 2004, p. 92). Support for migrant students is of a compensatory nature in Belgium and Austria - two old migrant receiving countries aimed at minimising disparity between native and migrant students. However, recognising the value and importance of migrants' linguistic heritage, Austria offers some mother-tongue teaching (European Commission, 2013).

Other European countries such as Italy, Cyprus, and Greece do not provide support at a national level because education providers do not have autonomy to adapt targeted support to individual migrants' needs nor to adjust national policies to the local circumstances. Instead, the onus regarding the inclusion of newly-arrived migrant children is placed on local schools and teachers. The concept of multicultural education with integrated support measures has been well developed in the UK. Germany appears to follow the UK multicultural approach. However, it is tailored to the German context characterised by the parallel support structures with separate instruction occurring outside of the main classroom (Qureshi and Janmaat, 2014). How Ireland compares to these various educational support models is discussed in the next section.

\section{IMMIGRATION TRENDS AND SUPPORT MEASURES FOR MIGRANT CHILDREN IN THE IRISH CONTEXT}

At the beginning of the economic downturn in Ireland, in 2008, there was a general expectation that most migrants would return to their countries of origin. Instead, the number of non-Irish nationals increased by 124,624 or 30 per cent (CSO, 2012, p. 33) between Census 2006 and Census 2011. The increase was particularly marked among Eastern European nationals, as shown in Figure 2.

[--- Figure 2 about here --- $]$ 
The number of migrant families with children in Ireland has also remained strong (CSO, 2012). According to the Department of Children and Youth Affairs (2012, p.29) in 2011, there were 93,005 migrant children in Ireland, accounting for eight per cent of the total child population.

While many European countries have adopted a number of different approaches to deal with migration-related diversity, such as assimilation, integration, interculturalism or multiculturalism (Gray, 2006; Mac Éinrí, 2007), developments in Ireland reflect wider debates about the impact of increased ethnic, cultural and linguistic diversity on traditional conceptions of citizenship and national identity, and how educational policies and curricula should respond to these challenges (O'Connor and Author 2, 2012; Author 2 and Ross, 2012). Despite some progress in providing targeted support for migrant children in Irish schools in the form of additional English language provision, the recent economic downturn has resulted in significant cuts in the education sector that have also reduced initiatives supporting linguistic and socio-cultural inclusion of migrant students. These cuts led to the discontinuation of Integrate Ireland Language and Training (IILT), which was established to meet the language and training needs of children from diverse cultural and educational backgrounds, particularly in secondary schools.

Over the years, a considerable body of research has built up on school inclusiveness in Ireland (Bryan, 2010; Smyth, 1999). However, few studies have specifically focussed on school-based support mechanisms available for migrants. The following sections provide a brief overview of the Irish education system at lower and upper secondary school level and the description of school-based support systems available to students.

\section{The Irish secondary education system}

In the Republic of Ireland young people enter lower secondary education ${ }^{2}$ at 12 or 13 years of age. Participation in full-time education is compulsory until the age of 16 , or three years of lower secondary education, whichever is later. In 2011/12, there were 723 secondary schools in Ireland, of which 376 were denominational voluntary secondary, 254 vocational and 93 community/comprehensive schools. Voluntary secondary schools, traditionally more academic in focus, are privately owned and controlled, mainly by religious orders. The vast majority of voluntary secondary schools are Catholic, with a small number of minority faith schools. Vocational schools are publicly owned and are administered by education and training boards (ETBs) and have greater practical orientation. There is also a small number 
(about $8 \%$ ) of private fee-paying schools. Community and comprehensive schools were established in an attempt to bridge the gap between the previously-mentioned two school types, by providing a broad curriculum catering for pupils of different backgrounds and ability levels. The types of school not only differ in their student composition, with a greater concentration of working-class and lower ability students in vocational schools (Hannan et al., 1996), they are often also more accessible to migrant students.

All European countries implement measures intended to combat educational disadvantage (European Commission, 2012). The Department of Education and Skills (DES) has a range of national programmes in place to address educational disadvantage throughout the Irish school system. 'Delivering Equality of Opportunity in Schools (DEIS) - an Action Plan for Educational Inclusion in Ireland' aims to address the educational needs of children from disadvantaged communities. ${ }^{3}$

\section{The Irish educational support model for migrant students}

It is argued that central to the education of the newly-arrived, multilingual students is a socioculturally supportive environment in the schooling context and in society (see Nilsson and Axelsson 2013). In the Irish context, the challenge at secondary level has been particularly acute for three reasons: Firstly, the older migrants are when they first enter the education system, the more they must learn in order to catch up with their English-speaking peers in terms of subject-specific terminology. Secondly, pre-service teacher training, for those who qualified some time ago and have not been able to benefit from revised programmes, may not have been adequately targeted to cater for non-English speaking students. Thirdly, much English language support at secondary schools is delivered not by specialists but by mainstream subject teachers who need to fill their timetable (Lyons and Little, 2009).

In Ireland, no mother tongue teaching is offered in schools to migrants; one reason for this may be the heterogeneity of migrant students and language diversity with over 200 languages being spoken (DES 2011). One of the key national support measures for migrant children in Irish schools is the provision of additional English language tuition, for those who do not speak English as their first language (see DES, 2012a). Consequently, several schools had built up a dedicated and skilled team of language support teachers. This support measure was reduced following the recession. In 2012-13, resources available for special needs education and language support were combined into a single allocation process with schools 
having autonomy on how to deploy resources between language and learning support (see DES, 2012).

The English language tuition, for two years, is not the only support available to migrant students. Migrant students can avail of general social and academic support (including the government-funded DEIS programmes) available for all students. In addition, parents are encouraged to attend parent-teacher meetings and other events organised by the schools. Furthermore, Ireland supports migrant students by enabling them to sit the Leaving Certificate (the final exam which gives access to higher education) in 15 EU languages. ${ }^{4}$

\section{METHODOLOGY}

This article presents secondary analysis of a large-scale mixed-methods study of school provision for migrant children in Irish primary and secondary schools (Smyth et al., 2009). This study was carried out in two stages. The first involved a national survey of school principals, representative of the population of schools in terms of school location and disadvantaged status; the second stage consisted of detailed case studies of schools. All the school names presented in this article are pseudonyms.

While the original study collected information from primary and secondary schools, this article only utilises data gathered from the latter. A postal survey was sent to all 733 principals of secondary schools. The survey was administered to all schools with a 63 per cent response rate, and participating schools were found to be representative of the population of schools in terms of sectoral classification, school location, gender mix and proportion of migrants. The national survey was used to determine the criteria for selecting six schools for more detailed case-study analysis (see Table 1 below). Within each of the schools, interviews were carried out with principals, a selection of teachers, home-school-community liaison coordinators (where present) and guidance counsellors. Interviews were carried out with small groups of second-year (aged 13) and fifth-year students (aged 16-17). These case studies yielded more detailed insights into issues relating to the experiences of Irish schools in catering for migrant students. Interviews were recorded, transcribed and coded using QSR Nvivo. In this article, we mainly draw on principal/teacher accounts to improve our understanding of support structures available to students in Irish secondary schools.

\section{[--- Table 1 about here ---]}


For the purpose of this paper, the data from the larger mixed-methods study has been supplemented by data from the latest Census (2011), and a comparative study of educational support for newly-arrived migrant children across European societies (European Commission, 2013) allowing us to examine the extent of formal and informal support in the Irish secondary schools in greater detail.

\section{MAIN FINDINGS}

Considering the challenges posed by large-scale immigration, this article aims to explore Irish schools' preparedness to cater for an increased diversity among the student body. The postal survey of secondary school principals showed that 28 per cent were able to do so 'to a great extent'; 51 per cent 'to some extent' and approximately 20 per cent reported being challenged by having migrants among their student body. The descriptive analysis of the data also showed that while there were no sectoral differences in the schools' ability to cater for migrant students, the DEIS schools were somewhat more likely to report being able to cater for migrant students, although the difference was not statistically significant. This finding may reflect additional funding provided by the state to DEIS schools that may make it easier for these schools to provide specific support for migrants. Small schools seemed more likely to be challenged by having migrant students in the school, possibly due to financial resources allocation (per capita per annum) but the finding was not statistically significant.

There are a number of different support measures in place in Irish schools for all students who need them, irrespective of their background, including class tutors and year heads, assistance from guidance counsellors and other personnel at school. Figure 3 presents an overview of more prevalent support measures available.

\section{[--- Figure 3 about here ---]}

In some cases, migrant students were expected to utilise the support systems already in place. According to a teacher at Huntington Road school '[support for migrants] would be the same as for our own students, the Chaplain and the career guidance [teacher], everybody is available to them.' Availability of a pastoral care team was mentioned by all case study schools as an important support measure: 
Well the first thing I would say to you, we have a pastoral care team in this school, and it's a very, very active pastoral care team. So at that meeting we are able to identify from what we know ourselves, from feedback from year heads, feedback from tutors, all of the students across the board, if there are difficulties, or if somebody is not responding the way they usually do, what the difficulties are?

(Teacher, Brayton Square)

As the number of migrant children in schools continued to increase, schools devised ways of catering for the needs of the new arrivals. The survey of school principals indicated that a variety of approaches was adopted (see Figure 4). The analysis of their responses revealed notable between-school rather than between-sector differences. While some schools opted for a mixed approach that included the use of a variety of approaches simultaneously, others adopted one main approach. These often included a mentoring system whereby another student was asked to look after the 'newcomer' and a pastoral care team (available to all students). Another widely used approach was the support from a teacher who, in some cases, was given a post of responsibility to look after newly-arrived migrant students.

\section{[--- Figure 4 about here ---]}

While targeted language support was funded by the government, in some cases, schools received assistance for specially targeted projects from other sources: 'we actually put on a summer school, during June and July, and the Department [of Education] have been good, and the Christian Brothers, and the St. Vincent de Paul, and the Health Board have given us a little bit of support' [Principal, Ashville Lane]. Assistance from a religious order in terms of setting up a buddy system or running various events that may act as ice breakers was also appreciated by the principal in Adwick Street. Of particular note is that student mentors or 'buddies' were used in a number of schools to provide informal support for migrant students.

The interviews with principals revealed that important informal support measures included sport. 'We have two girls who, you know have very good English, they're on our basketball team, they're totally integrated and that. There's another girl who started only a couple of weeks ago who has integrated really quickly, again because she has a common language of sport' (Principal, Lowfield Street). Peers in the school have a strong impact on how well migrant students settle in the school and their general sense of belonging. While a 
supportive atmosphere is likely to help them to get used to the new environment, bullying can often undermine the confidence and self-esteem of students. The principals in 43 per cent of schools had a policy in place that specifically addressed racial harassment. In addition, several schools had a written policy on interculturalism and anti-racism, either included in the school development plan (17\%) or as part of some other document $(12.3 \%)$. Other measures included proactive approaches when addressing difference and bullying:

Well we'd be very proactive in the RE class, we've signs up all over the place. The international week, racism isn't tolerated. Every kid would be told when they come in in first year ... anti-bullying; this includes calling people from different countries names and stuff like that. So they'd all be aware of it.

(Teacher, Ashville Lane)

Academic support measures in Irish schools largely involved language and learning support. Several teachers and principals highlighted the difficulties involved in class placement of newly-arrived migrant students who had no English and make sure they have the academic support they need:

If they have English and I can assess them. If they haven't got English and a lot don't, not a word, I just take a chance and put them into the class where they get maximum support. We have what we call a middle band, we don't stream but we band, in the middle band we have maximum support, mostly there'll be two or three teachers to a class there with SNAs [special needs assistants], maximum support.

(Principal, Brayton Square)

In addition to this, a lack of continuous English language support for migrant students was also highlighted in the interviews:

There was a thing, they could only get support for two years, and that was it. So if a kid came from the Congo in 5th class primary and got two years language support there, nothing in the secondary. I mean what kid will cope with that? Ridiculous, two years! In a foreign country with a foreign language trying to learn it and trying to do an exam and everything, crazy.

(Principal, Brayton Square) 
The English language tuition support is the only targeted support in Irish secondary schools, but this provision ends after the introductory years. As pointed by Cummins (1981), it may take up to nine years to reach the level of native speakers for academic language in the second language.

Supportive schools strive to engage parents and the community. In the survey, the principals were asked about parental involvement in the school. Sixty-three per cent reported that nearly all parents attend parent-teacher meetings. Principals of voluntary secondary schools were more likely to report that this was the case compared to the other two sectors $(\mathrm{p}<.000){ }^{5}$ These principals were also more likely than principals of vocational and community/comprehensive schools to note that the statement 'parents help children with schoolwork' was 'true of nearly all parents' $(\mathrm{p}<.000)$. A notable proportion of principals reported that some parents contact the school only when their child is experiencing a problem: 32 per cent of principals reported that this is 'true for nearly all', with principals from voluntary secondary schools somewhat more likely to do so $(\mathrm{p}<.008)$. The principals in DEIS schools were less likely to report that parents attend meetings $(p<.000)$ or help their children with schoolwork $(\mathrm{p}<.000)$.

Parental involvement has been identified as an important support for migrant children. The interviewees in our study noted that parental involvement may vary among Irish as well as among migrant parents:

Some would be very much involved and others wouldn't because you know society has changed and there's so many other demands or interests that, you know, children go off to school and they come home and they don't get involved beyond the parent/teacher meetings, bar if there's a difficulty. And then you have again a different type of parent who's constantly in touch and checking up and wanting to know.

(Principal, Grange Park)

In this study, only eight per cent of principals reported that lack of such support contributes to the settling in difficulties of migrant children 'a great deal.' In order to address poor English language skills of some migrant parents, 17 per cent of all schools had organised language courses for migrant parents. Compared to the other two school sectors, voluntary secondary schools were least likely to do so $(9 \% ; \mathrm{p}<.000)$. 
During the interviews, some principals highlighted the need to have more centralised support from the Department of Education and greater collaboration between schools in sharing good practice and ideas:

At a Department level there needs to be a unit that takes charge of everything, bearing in mind that it's more than just the curriculum, that there's the integration, there's the sport, there's the socialisation, there's everything.

(Principal, Lowfield Street)

There's not an awful lot of information available, vis-à-vis what the different schools are doing, and it's ridiculous, we've looked for a national co-ordinator from the Department, in the voluntary sector, and that hasn't been forthcoming, so that the wheel needn't be reinvented, in certain places, and also there could be a sharing of good practice, and people would have a source to go to, when we had anything we needed, but that hasn't happened.

(Principal, Ashville Lane)

Schools with a proactive approach to migrant inclusion, good leadership and a whole school stance on student support are more likely to meet the challenges rather than schools where staff are resistant to change and report limited interaction with parents (Mittler 2000; Smyth and McCoy, 2009).

As shown, the accounts of the principals representing different secondary school sectors with varying proportions of migrants and supports available did not differ to any great extent regarding support measures used; the analysis of the interviews largely confirmed what was found in the survey data. One of the most consistent findings from this study is the fact that schools were relatively unprepared for the arrival of migrant students. At the same time, in order to respond to the needs of a variety of newcomers, they devised a variety of approaches and included special clauses regarding tolerance and anti-racial harassment in their school policies.

Interestingly, the measures put in place by schools did not vary depending on the number of migrants in each school. This could be explained by the fact that the number of migrant students in Irish secondary schools is still quite small. At the same time, the approach adopted in Irish schools could be criticised. Firstly, migrant students can have very different needs compared to other at-risk-students in Irish schools. Secondly, as argued by Booth 
(1996), development of comprehensive community education is primarily concerned with fostering participation for everyone and reducing all exclusionary pressures. Following cuts in the education sector resulting from the economic downturn since 2008, Irish schools have been left to their own devices, subsequently employing various support measures that they have already at their disposal. Challenges that Irish schools face in the context of migration can be summed up in a quote from a principal from Ashville Lane, noting that the unpredictable nature of migrants looking for a place in the school and diversity among the new arrivals makes it difficult to plan for the provision of migrant students:

The international students, and that's an unknown quantity because we don't know how many, or where, or, and then there's great diversity within that group as well, so there are lots of things impacting on us.

(Principal, Ashville Lane)

Finally, in the survey, the principals were asked about intercultural education in the context of textbooks, teaching resources and teachers' preparation for teaching in a multicultural setting. The survey analysis identified strong dissatisfaction among the principals across all secondary schools with pre-service and in-service provision with regard to teaching in a (newly) multicultural setting. Over 63 per cent of them felt that pre-service education does not adequately prepare teachers for teaching in a newly multicultural classroom. 66 per cent of principals also expressed their dissatisfaction with in-service education. 93 per cent of principals felt that more in-service education in intercultural education was needed:

[Teachers] They're not [prepared], that's it, they're not, what they learn, and what they pick up in here ...they were shell-shocked in the beginning, ... as far as I can see, in College they're not being taught a thing about foreign national students, you know, that's what I take out of it anyway ... And not one of them comes to me and says "oh yea we did that in College, we did that with the foreign [students], you know...

(Principal, Brayton Square)

The survey was carried out during pre-recession time when the inflow to Ireland was remarkable. Now the situation has changed, with some colleges offering modules in intercultural education as part of initial teacher education. However, as noted by Ashville 
Lane's principal, '...issues relating to interculturalism, or multiculturalism, and the teaching of these, should now form part of teacher training courses, as a matter of form, just should be there'. The principals considered intercultural education in the school inadequate. They highlighted the need for further resources and continuous teaching support and training specifically geared towards meeting the needs of newcomer students.

The Irish example indicates that ongoing investment in education is necessary. Nurturing earlier levels of education lays the foundation to advance to higher education (see McGorman and Sugrue, 2007). Ireland was taken by surprise by the substantial influx of migrants over a short period of time. More importantly, it was not anticipated that migrants would stay and settle, hence the lack of specific support measures with the exception of extra English language support. Regardless of diversification of practical approaches to the concept of inclusion, a fully inclusive approach as advocated by Booth et al. (2000) would require establishing inclusive values, organising support for diversity, producing an inclusive school development plan and reviewing it on a regular basis to ensure enhancement.

\section{CONCLUSION}

Drawing on previous research and comparison of various support models available for migrants in the EU as well as secondary analysis of data on migrant students in Ireland, the article has shown that addressing the needs of a newly culturally and linguistically diverse student body is not only challenging, but that approaches taken can vary across schools, arguably resulting in different experiences of students (Author 3 et al., 2012b). At the same time, schools differ regarding their profile and ethos and it could be contended that flexibility is required in addressing the needs of migrant students. These needs may vary according to levels of English language proficiency, literacy and migration background (e.g. refugees and asylum seekers).

This study found that support provided for newly-arrived migrant children in Ireland differs to some extent from that of other NAMS study countries. While Ireland offers linguistic and educational support, similar to other NAMS study countries, what makes Ireland different is that the students are expected to feed into already existing support structures for disadvantages students in general. All Irish schools have supports in place for at-risk students, including a pastoral care team and class tutor system, with additional support measures to tackle educational disadvantage provided under the DEIS initiative. 
For migrant students, the key government support includes additional English language support, and the provision of additional support is largely down to the approach taken by individual schools. While, in theory, the schools in our study largely adopted an inclusive approach in catering for migrants, in some cases the principals considered support insufficient. One of the limitations of the study is that the large study did not collect information on the effectiveness of the approaches used - this topic merits further research including information to be collected from migrant children. However, the main contribution of this article lies in the fact that it provides a snapshot of the situation at the end of the 'Celtic Tiger' era, and just after. Further research is warranted that would take a closer look at children's perspectives in order to establish the effectiveness of school support approaches used, subsequently assessing how inclusive Irish schools are.

Migrant students are more likely to benefit from schools with an inclusive approach, as they are more likely to avail of equality of educational opportunities. Nevertheless, in order to provide truly inclusive education, further changes must be introduced in both preservice teacher education and availability of in-service training in intercultural education for all teachers.

As shown in this article, Irish secondary schools differ regarding support measures for migrant students. Over the years, Ireland has developed systems for welcoming migrant students with the availability of assessment prior to schooling (assessment of language competences) and support programs for underachieving students (DEIS programmes), discussed earlier. Yet, it has been acknowledged that educational disadvantage coupled with economic disadvantage is likely to impact on the future life chances of young migrants in Ireland (see Author 3 et al., 2012; Devine, 2011, 2012). The main issues arising from the findings indicate that current support in Irish secondary schools is not sufficient and there is a need for ongoing improvement of linguistic skills and continuous teaching support with a view of creating a positive school environment. Without financial support for extra-curricular activities to help newcomers with their integration, Irish schools are largely left to their own devices. Without adequate resources supporting teachers to work effectively in linguistically and culturally diverse contexts (see also Schecter and Cummins 2003), it is almost impossible to focus on developing and improving supportiveness, which undeniably would mean enhancing inclusiveness.

Giving the changing nature of the school population across the EU, the provision of language support has been an important policy response implemented by old migration and new migration countries (European Commission, 2012). Targeted support extends to 
linguistic support for migrant students, but this provision ends after the introductory years. English language proficiency or a lack thereof continues to affect the educational experiences of migrant students. There is thus a real need for inclusive education policies and school practices that benefit all students and will ensure that newcomers have equal life chances.

The Department of Education and Skills envisages creating a highly-educated and globally competitive workforce through increased accountability in Irish schools (Sloane et al., 2013). However, in the current economic climate this cannot be achieved without developing inclusiveness through formal and informal support measures, without continuous English language support for migrant students, nor without building inclusive communities of practice to ensure long-term development and educational success of all students.

\section{NOTES}

1. The Irish second-level curriculum is divided into two cycles: a three-year 'junior cycle' ending with the Junior Certificate examination, and a two-year 'senior cycle' ending with the Leaving Certificate examination.

2. Lower and upper secondary schooling is commonly referred to as second-level or post-primary schooling/sector in the Republic of Ireland.

3. Irish schools are identified for participation in DEIS programme based on the predominance of certain household characteristics such as lone parenthood or unemployment (Smyth and McCoy, 2009). DEIS schools are less likely to be oversubscribed thus they are more accessible for migrant students (Byrne et al., 2010). The programmes offered at secondary level include: a literacy and numeracy strategies under the Junior Certificate School Programme (JCSP); the Leaving Certificate Applied (LCA); the School Completion Programme; additional Guidance Counselling provision; social inclusion programmes; Home/School/Community Liaison (HSCL); and provision for students with special needs.

4. These include: Bulgarian, Czech, Dutch, Danish, Estonian, Finnish, Greek (modern), Hungarian, Latvian, Lithuanian, Polish, Portuguese, Romanian, Slovakian and Swedish.

5. In order to test the relationship between the variables, a Pearson's chi square test of significance was used. A significance level of $\mathrm{p}<.001$ means that the likelihood is less than one in a thousand that this relationship would occur by chance. 


\section{REFERENCES}

Ainscow, M. (1999) Understanding the Development of Inclusion Schools (London, Falmer Press).

Ainscow M, Booth, T, Dyson, A, Farrell, P, Frankham, J., Gallannaugh, F., Howes, A, and Smith, R. (2006) Improving Schools, Developing Inclusion (London, Routledge).

Armstrong, F. (2009) Integration or inclusion? Policy, diversity and education and the 'equality' agenda in England. Available at: http:/gridsitaly.net/wpcontent/uploads/2011/11/page1_7.pdf (accessed 5 February 2015).

Barg, K. (2013) The influence of students' social background and parental involvement on teachers' school track choices: reasons and consequences, European Sociological Review, 29 (3), 565-579.

Booth, T. (1996) A perspective on inclusion from England, Cambridge Journal of Education, $26(1), 87-99$.

Booth, T., Ainscow, M., Black-Hawkins, K., Vaughan, M. and Shaw, L. (2000) Index of Inclusion (Bristol, Centre for Studies on Inclusive Education).

Bradshaw, C., Pas, E., Bloom, J., Barrett, S., Hershfeldt, P., Alexander, A., McKenna, M., Chafin, A., and P. Leaf (2012) A state-wide partnership to promote safe and supportive schools: The PBIS Maryland Initiative, Administration and Policy in Mental Health and Mental Health Services Research, 39 (4), 225-237.

Bragg, S and Manchester H. (2011) Creativity, School Ethos and Creative Partnerships Programme (Manchester, The Open University Press).

Bryan, A. (2010) Corporate multiculturalism, diversity management, and positive interculturalism in Irish schools and society, Irish Education Studies, 29 (3), 253-271.

Byrne, D., McGinnity, F., Smyth, E., and Darmody, M. (2010) Immigration and school composition in Ireland, Irish Educational Studies, 29 (3), 271-288.

Cebolla-Boado, H. (2007) Immigrant concentration in schools: Peer pressure in place? European Sociological Review, 23 (3), 341-536.

Central Statistics Office (2012) Population and Migration Estimates: April 2012 (Dublin, $\mathrm{CSO})$.

Corbett, J. (1999) Inclusive education and school culture, International Journal of Inclusive Education, 3 (1), 56-61.

Corbett, P. (2001) Teaching approaches which support inclusive education: a connective pedagogy, British Journal of Special Education, 28 (2), 55-59. 
Cummins, J. (1981) Age on arrival and immigrant second language learning in Canada: a reassessment, Applied Linguistics, II (2), 132-149.

DEIS (2005) Delivering Equality of Opportunity In Schools: An Action Plan for Educational Inclusion (Dublin, Government Publications).

Department of Education and Science (2005) Guidelines for Second Level Schools on the Implications of Section 9c of the Education Act 1998 relating to Students' Access to Appropriate Guidance (Dublin, DES).

Department of Children and Youth Affairs (2012) State of the Nation's Children: Ireland 2012 (Dublin, Government Publications).

Department of Education and Skills (2012) Circular 0009/2012: Staffing Arrangements in Secondary Schools for the 2012/13 School Year (Dublin, DES).

Department of Education and Skills (2011) Literacy and Numeracy for Learning and Life: The National Strategy to Improve Literacy and Numeracy among Children and Young People 2011-2020 (Dublin, DES).

Devine, D. (2011) Securing migrant children's educational well-being: Perspective of policy and practice in Irish schools. In M. Darmody, N. Tyrrell, and S. Song (Eds.) The Changing Faces of Ireland: Exploring Lives of Immigrant and Ethnic and Minority Children (Rotterdam, Sense), 73-88.

Devine, D (2012) Immigration and Schooling in Ireland: Making a Difference? (Manchester, Manchester University Press).

Devine, D., Fahie, D. and McGillicuddy, D. (2013) What is 'good' teaching? Teacher beliefs and practices about their teaching, Irish Educational Studies, 32 (1), 82-108.

Eliot, M; Cornell, D., Gregory, A. and Fan, X. (2010) Supportive school climate and student willingness to seek help for bullying and threats of violence, Journal of School Psychology, 48 (6), 533-553.

European Commission (2008) Education and Migration: Strategies for Integrating Migrant Children in European Schools and Societies (Brussels, European Commission).

European Commission (2012) Education and Training Monitor 2012 (Luxembourg, Publications Office of the European Union).

European Commission (2013) Educational Support for Newly Arrived Migrant Children (Luxembourg, Publications Office of the European Union).

Fertig, M. (2012) Educational leadership and the Capabilities Approach: Evidence from Ghana, Cambridge Journal of Education, 42 (3), 391-408. 
Gray, B. (2006) Migrant integration policy: A nationalist fantasy of management and control, Translocations, 1 (1), 121-141.

Gorard, S. (2013) What difference do teachers make? A consideration of the wider outcomes of schooling, Irish Educational Studies, 32 (1), 69-82.

Hannan, D.F., Raffe, D. and Smyth, E. (1996) Cross-National Research on School to Work Transitions: An Analytical Framework (Paris, OECD).

Hersi, A.A. (2011) Immigration and resiliency: Unpacking the experiences of high school students from Cape Verde and Ethiopia, Intercultural Education, 22 (3), 189-202.

Kitching, K. (2012) Understanding class anxiety and 'race' certainty in changing times: Moments of home, school, body and identity configuration in 'new migrant' Dublin. In J. Bhopal and J. Preston (Eds.) Intersectionality and Race in Education (London, Routledge), 158-177.

Konu, A. and Rimpela, M. (2002) Well-being in schools: Conceptual model, Health Promotion International, 17 (1), 79-87.

Lizzio, A. Wilson, K. and Simons, R. (2002) University students' perceptions of the learning environment and academic outcomes: Implications for theory and practice, Studies in Higher Education, 27 (1), 27-52.

Lyons, Z., and Little, D. (2009) English Language Support in Irish Secondary Schools: Policy, Challenges and Deficits (Dublin, Trinity College Dublin).

Mac Éinrí, P. (2007) Integration models and choices. In B. Fanning (Ed.) Immigration and Social Change in Ireland (Manchester, Manchester University Press).

Mannitz, S. (2004) The place of religion in four civil cultures. In W. Schiffauer, G. Baumann, R. Kastoryano, and S. Vertovec (Eds.) Civil Enculturation: Nation-State, Schools and Ethnic Difference in Four European Countries (Brooklyn, Berghahn Books), 88-118.

Marzo, L. (2011) Study on Educational Support for Newly Arrived Migrant Children (Luxembourg, Publications Office of the European Union).

McGorman, E., and Sugrue, C. (2007) Intercultural Education: Primary Challenges in Dublin 15 (Dublin, Department of Education and Science).

Mittler, P. (2000) Working Towards Inclusive Education: Social Contexts (London, David Fulton).

Nilsson, J. and Axelsson, M. (2013) 'Welcome to Sweden': newly arrived students' experiences of pedagogical and social provision in introductory and regular classes, International Electronic Journal of Elementary Education, 6 (1), 137-164. 
Osterman, K.F. (2000) Students' need for belonging in the school community, Review of Educational Research, 70 (3), 323-367.

Qureshi, Y., F. and Janmaat, J.G. (2014) Diverging or converging trends: an investigation of education policies concerning the incorporation of ethnic minority children in England, France and Germany, Compare: A Journal of Comparative and International Education, 44 (5), 710-731.

Rangvid, B.S. (2007) Living and learning separately? Ethnic segregation of school children in Copenhagen, Urban Studies, 44 (7), 1329-1354.

Schecter, S. and Cummins, J. (2003) Multilingual Education in Practice: Using Diversity as a Resource (Pearson Education Canada).

Smyth, E. (1999) Do School Differ? Academic and Personal Development among Pupils in the Second-Level Sector (ESRI, Oak Tree Press).

Smyth, E., Darmody, M., McGinnity, F., Byrne, D. (2009) Adapting to Diversity: Irish Schools and Newcomer Students (Dublin, ERSI).

Smyth, E., and McCoy, S. (2009) Investing in Education: Combating Educational Disadvantage (Dublin, ESRI).

Sloane, C.F., Oloff-Lewis, J. and Kim, S.H. (2013) Value-added models of teacher and school effectiveness in Ireland: wise or otherwise? Irish Educational Studies, 32 (1), $37-69$.

Velden, R .K.W and Wolbers, M.H.J. (2007) How much does education matter and why?: The effects of education on socio-economic outcomes among school-leavers in the Netherlands, European Sociological Review, 23 (1), 65-80.

Winter, E., and O'Raw, P. (2010) Literature Review of the Principles and Practices relating to Inclusive Education for Children with Special Educational Needs (Trim, National Council for Special Education). 
Figure 1: Distribution of support measures of 15 EU-countries

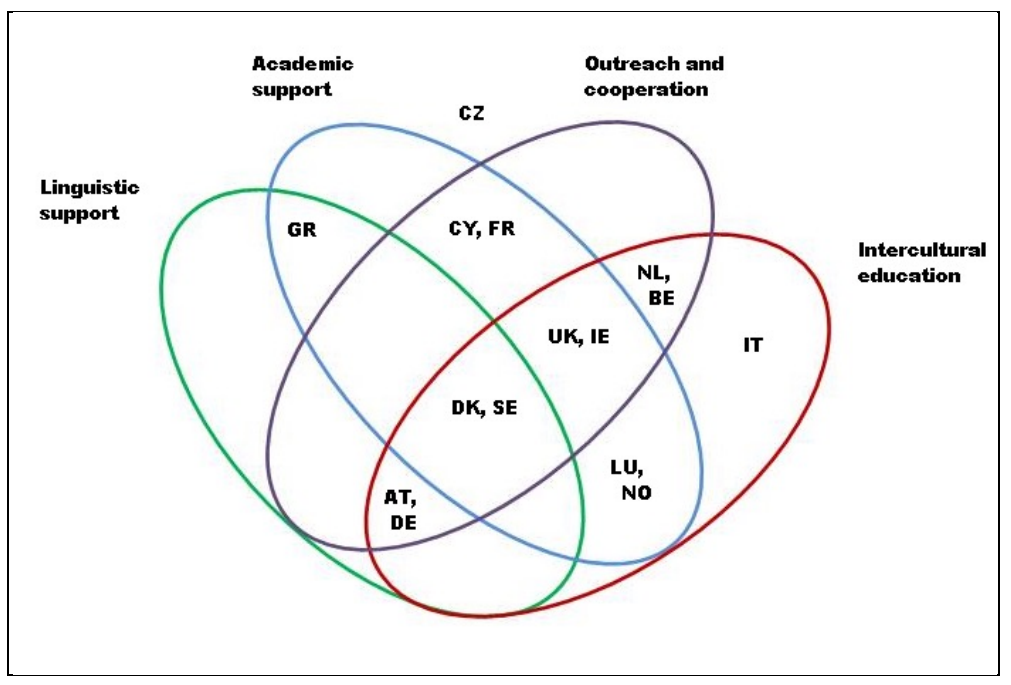

Source: Marzo, NAMS (2011) 
Figure 2: Persons usually resident by nationality for selected countries 2006-2011

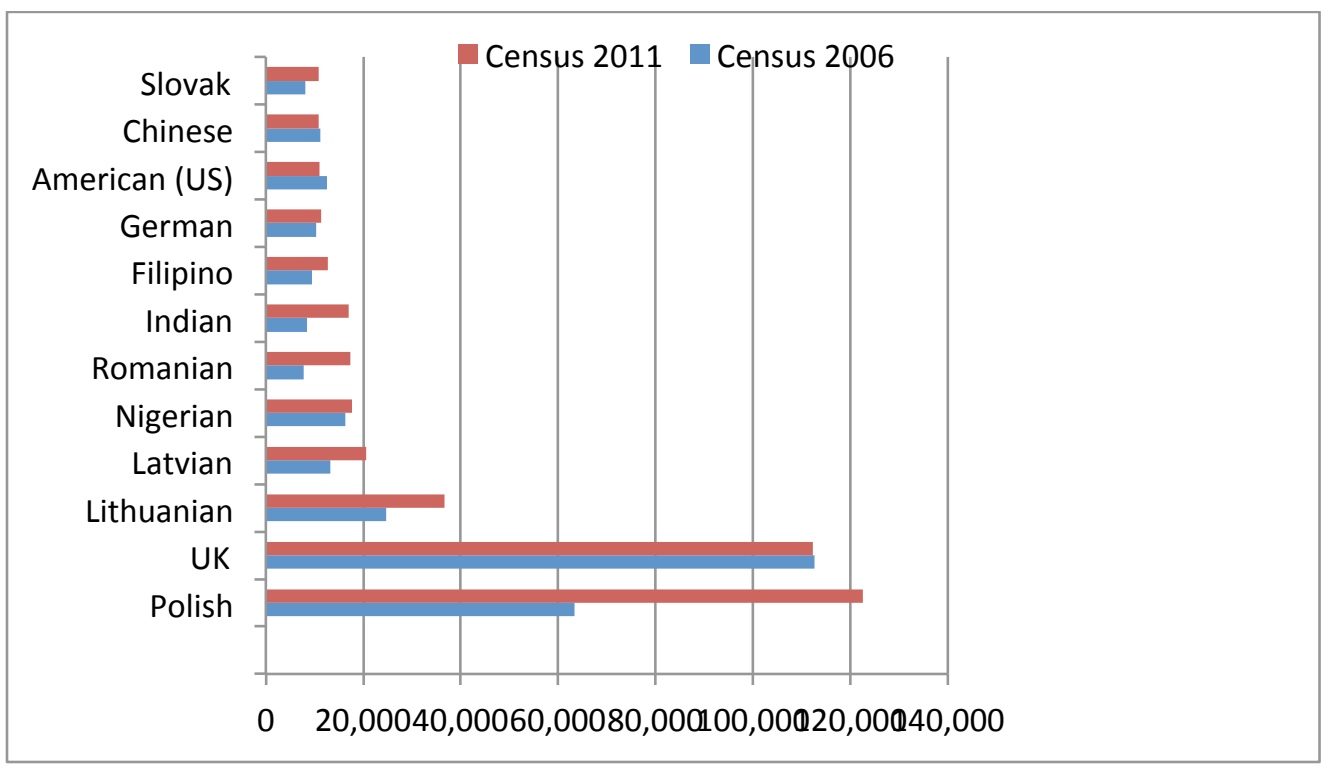

Source: CSO, 2012 
Table 1: Case-study schools

\begin{tabular}{|l|l|l|l|l|l|l|}
\hline & $\begin{array}{l}\text { Huntington } \\
\text { Road }\end{array}$ & $\begin{array}{l}\text { Bentham } \\
\text { Street }\end{array}$ & $\begin{array}{l}\text { Wulford } \\
\text { Park }\end{array}$ & $\begin{array}{l}\text { Brayton } \\
\text { Square }\end{array}$ & $\begin{array}{l}\text { Ashville } \\
\text { Lane }\end{array}$ & $\begin{array}{l}\text { Lowfield } \\
\text { Street }\end{array}$ \\
\hline $\begin{array}{l}\text { DEIS } \\
\text { status }\end{array}$ & Non-DEIS & Non-DEIS & Non-DEIS & DEIS & DEIS & Non-DEIS \\
\hline $\begin{array}{l}\text { Sector and } \\
\text { gender } \\
\text { mix }\end{array}$ & $\begin{array}{l}\text { Voluntary } \\
\text { secondary } \\
\text { (girls) }\end{array}$ & $\begin{array}{l}\text { Community/ } \\
\text { comprehensive } \\
\text { (coeducational) }\end{array}$ & $\begin{array}{l}\text { Vocational } \\
\text { (coeducational) }\end{array}$ & $\begin{array}{l}\text { Community/ } \\
\text { comprehensive } \\
\text { (coeducational) }\end{array}$ & $\begin{array}{l}\text { Voluntary } \\
\text { secondary } \\
\text { (boys) }\end{array}$ & $\begin{array}{l}\text { Voluntary } \\
\text { secondary } \\
\text { (girls) }\end{array}$ \\
\hline $\begin{array}{l}\text { Proportion } \\
\text { of } \\
\text { migrants }\end{array}$ & Low/medium & Low/medium & High & High & High & $\begin{array}{l}\text { Low/ } \\
\text { medium }\end{array}$ \\
\hline
\end{tabular}


Figure 3: Summary of pre-existing support measures for all students in Irish schools

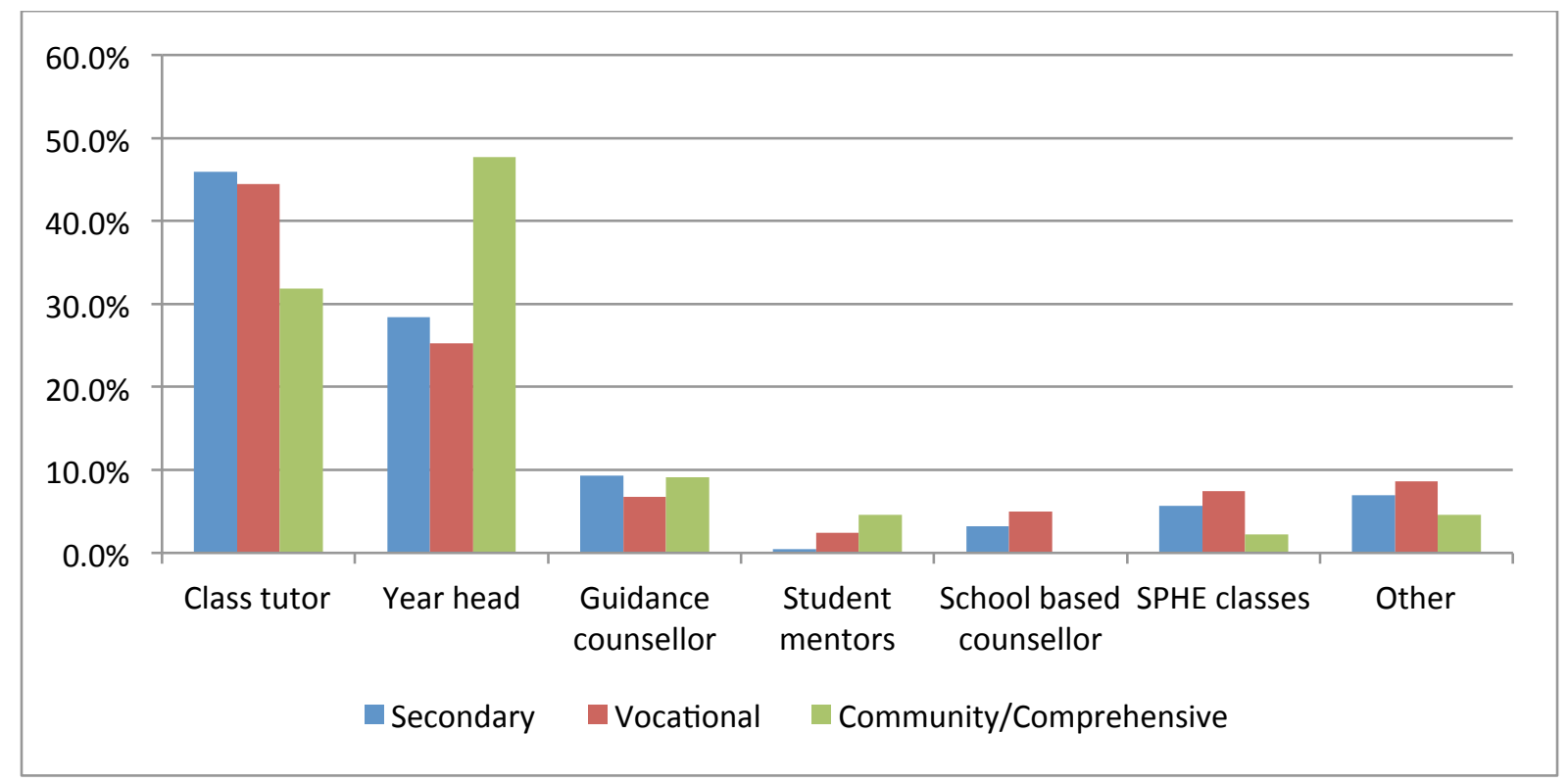


Figure 4: Summary of support measures used in Irish schools to help newcomers settle in

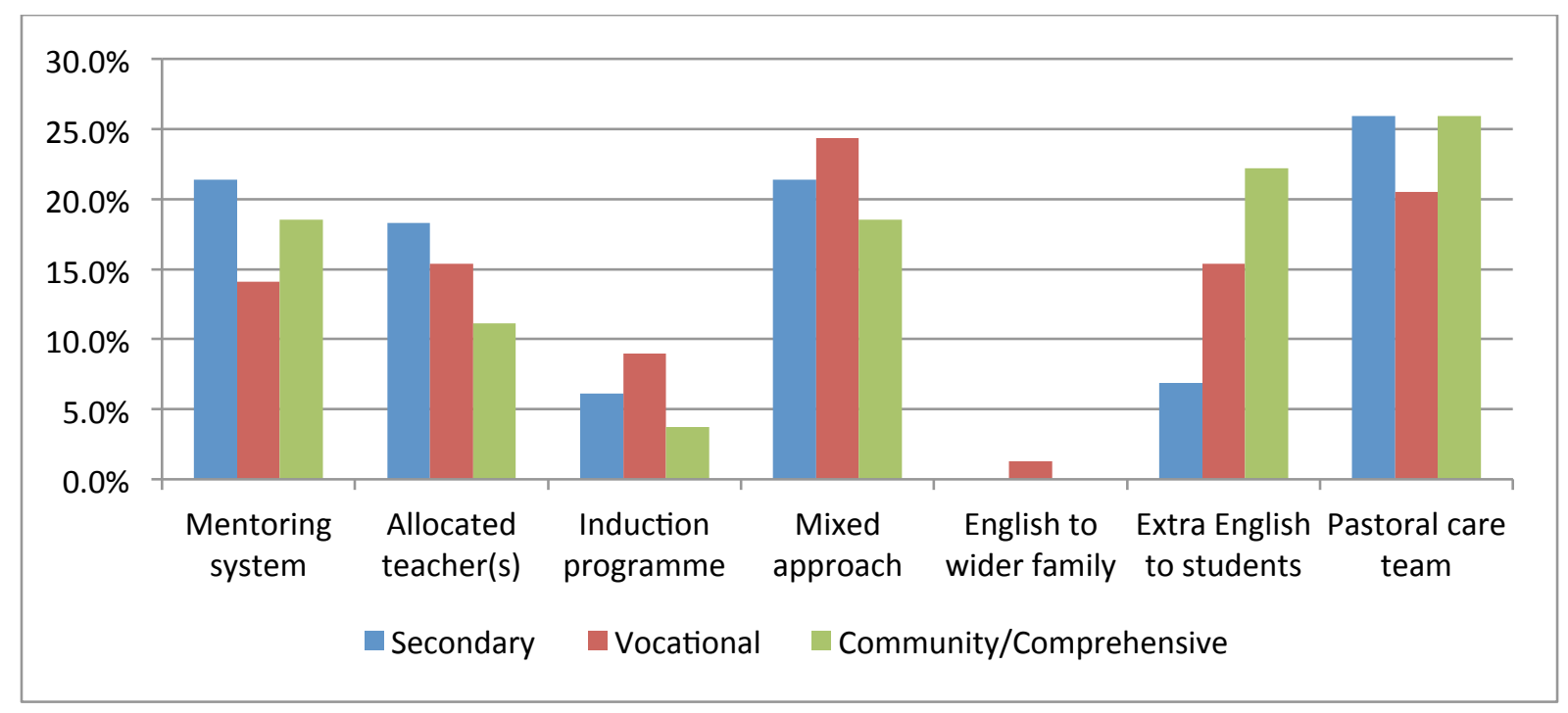

